Article

\title{
Weight-Vibration Pareto Optimization of a Triple Mass Flywheel for Heavy-Duty Truck Powertrains
}

\author{
Viktor Berbyuk (D) \\ Department of Mechanics and Maritime Sciences, Chalmers University of Technology, \\ SE-412 96 Gothenburg, Sweden; viktor.berbyuk@chalmers.se
}

Received: 31 July 2020; Accepted: 28 August 2020; Published: 31 August 2020

check for updates

\begin{abstract}
Enhanced efficiency of heavy-duty truck powertrains with constraints imposed on noise, vibration, and harshness requires novel solutions for torsion vibrations attenuation. In the paper, the weight-vibration Pareto optimization problem for a novel vibration absorber, a triple mass flywheel, for application in heavy-duty truck powertrains is considered. Global sensitivity analysis and Pareto optimization method are used to design a novel vibration absorber. The optimization method attempts to minimize oscillations of the torque at the transmission input shaft as well as to minimize total mass inertia of the absorber. It is shown that there exists a Pareto front between the measure of the attenuation of oscillations of the torque and the total mass inertia of a triple mass flywheel. The optimized design parameters for the absorber are obtained that provide the best attenuation of oscillations of the torque at the transmission input shaft for different mean values of the engine driving torque. The analysis shows real evidence of the feasibility of the application of this concept of vibration absorbers in heavy-duty truck powertrains. It is also shown that optimized design parameters of a triple mass flywheel put this concept in a superior position in comparison with a dual mass flywheel.
\end{abstract}

Keywords: triple mass flywheel; heavy-duty truck powertrain; weight-vibration Pareto optimization; dual mass flywheel; torsional vibration absorbers

\section{Introduction}

The demand for higher efficiency of vehicle powertrain systems requires the development of novel drivetrain functional components. For instance, the heavy-duty truck industry struggles to develop down-sized and down-speeded engines and higher cylinder pressure. This leads to more excitation coming to the transmission and requires advancing the available solutions for noise and vibration attenuation, making the design of efficient vibration absorbers for drivetrains of heavy-duty trucks a big challenge.

One of the well-known vibration absorbers for drivetrains of ground vehicles is a dual mass flywheel (DMF). The DMF was a subject of intensive research [1-8], and has been used in passenger car since the 1980s [9]. To increase the quality of vibration attenuation, the concept of a DMF began to be modified by incorporating additional spring-mass components by combining with a so-called centrifugal pendulum vibration absorber, and additional absorbers with smooth and non-smooth nonlinearities [9-14]. Interesting research is ongoing on the development of controlled DMF for torsional vibration attenuation in powertrain systems using controllable magnetorheological elastomeric springs and an appropriate controller design [15-17].

In heavy-duty truck drivetrains, the conventional single mass flywheel is still in use. However, increasing demand for a higher efficiency of truck powertrains requires novel solutions. The research is ongoing both in academia as well as in industry to understand if a DMF as well as other multiple-mass absorbers are suitable for application in powertrains of heavy-duty trucks [18-24]. The idea of tuned 
mass damper, successfully used in a variety of engineering applications [25-29], was also applied to modify a DMF performance. In recent work $[19,21,22]$, DMFs with and without a tuned mass damper were studied for application to the powertrain of a heavy-duty truck. It was concluded that an optimally design tuned mass damper could reduce the amplitude of oscillations of the torque at the transmission input shaft more than corresponding conventional DMF. Using multiple-mass absorbers, for example, a DMF with a tuned mass damper, a decrease in the level of vibration in heavy-duty truck powertrains is feasible. However, most probably, a larger installation space will be needed for novel absorbers [19,22-24]. The latest calls for optimization of multiple-mass absorbers consider constraints on installation space, weight, reliability, cost, and so on. Different numerical methods are available to optimize structure and performance of engineering systems; see, for example, [30-36]. A new method for optimizing the parameters of torsional vibration absorbers is presented in [32]. Topology optimization problems with specified eigenfrequencies and eigenmode shapes are considered in [34]. Design optimization for composite structures operating in acoustic environments by using Newton's method is studied in [35].

In the present paper, both the requirement on the level of vibration attenuation and the restrictions on the installation space and weight are combined by considering the weight-vibration Pareto optimization (WV-PO) problem of torsional vibration absorbers for application in heavy-duty truck powertrains. The bi-objective optimization problem is solved using the genetic algorithman optimization technique that has biological origins and works based on probabilistic searching [33]. Two concepts of vibration absorbers are studied: a triplemass flywheel and a conventional DMF. A triple mass flywheel (TMF) is a novel concept of multiple-mass vibration absorbers with several advantages in comparison with a conventional DMF [37]. The TMF is described and the mathematical model of a generic vehicle drivetrain equipped with this absorber is derived in Section 2 . The results of the global sensitivity analysis of a TMF are presented in Section 3, showing the effect of variation of structural parameters on vibration attenuation, absorber's total mass inertia, and friction between the flywheels. The problem of weight-vibration Pareto optimal design of a TMF is formulated with focus on their application in heavy-duty trucks powertrains and the solution is presented in Section 4. The obtained results are discussed in Section 5 in comparison with the corresponding results for weigh-vibration Pareto optimized DMF. The paper is finalized with conclusions and an outline of future research.

\section{Modelling}

Figure 1 shows a schematic illustration of a portion of a vehicle drivetrain. The drivetrain includes an engine (E), a triple mass flywheel (TMF), and a load transmission system (LTS) that receives driving power from a TMF. The TMF comprises a primary wheel $p w$ that receives rotational driving torque from engine, a tertiary wheel $t w$, and a secondary wheel $s w$ that provides the driving power to the transmission system.

In Figure $1, \varphi_{p}, \varphi_{t}, \varphi_{s}$ are absolute angles of rotation of the $p w$, the $t w$, and the $s w$, respectively; $J_{p}, J_{t}, J_{s}$ are axial moments of inertia of the $p w$, the $t w$, and the $s w$, respectively; $k_{p s}, c_{p s}, k_{p t}, c_{p t}, k_{t s}, c_{t s}$ are coefficients of torsional stiffness and torsional damping between the $p w$ and the $s w$, the $p w$ and the tw, and the $t w$ and the $s w$, respectively. The crank mechanism inertia is not included in the $J_{p}$, and the inertia of the members located downstream the secondary flywheel is not included in the $J_{s}$.

Using a free-body diagram, the equations of torsional vibration dynamics of the drivetrain equipped with a TMF are written as follows:

$$
J_{p} \ddot{\varphi}_{p}=T_{e}(t)-T_{f p s}(t)-T_{f p t}(t), \quad J_{s} \ddot{\varphi}_{s}=T_{f p s}(t)+T_{f t s}(t)-T_{g}(t), \quad J_{t} \ddot{\varphi}_{t}=T_{f p t}(t)-T_{f t s}(t) .
$$

Here, in Equations (1) $T_{e}(t), T_{g}(t)$ are the engine driving torque and the torque at the transmission input shaft, respectively. 


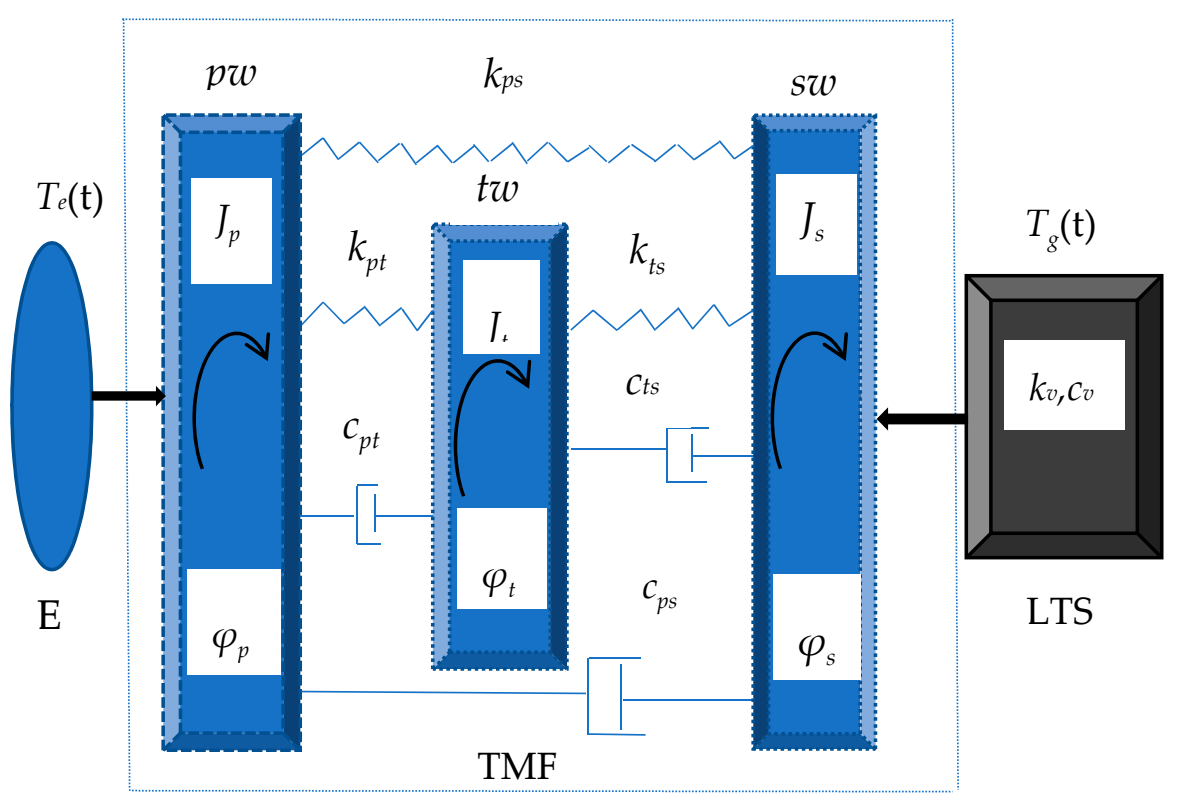

Figure 1. A schematic illustration of a portion of a vehicle drivetrain with a triple mass flywheel (TMF).

LTS, load transmission system.

To evaluate the friction torques $T_{f p s}(t), T_{f p t}(t), T_{f t s}(t)$ at the stiffness-damping interface between the wheels of a TMF, it is important to choose the appropriate friction model. Early on, this question was studied using simulations and experimental data obtained on a test rig with the dual mass flywheel [18,24]. In simulations, the non-linear LuGre friction model was used [38]. It was shown that the proposed system model with LuGre friction reproduces the behavior of the dual mass flywheel sufficiently well, and the viscous part of the friction is dominant for the analyzed cases.

In this work, the torques at the stiffness-damping interface between the wheels of a TMF will be defined by the following expressions:

$$
\begin{gathered}
T_{f p s}(t)=k_{p s}\left(\varphi_{p}-\varphi_{s}\right)+c_{p s}\left(\dot{\varphi}_{p}-\dot{\varphi}_{s}\right), \quad T_{f p t}(t)=k_{p t}\left(\varphi_{p}-\varphi_{t}\right)+c_{p t}\left(\dot{\varphi}_{p}-\dot{\varphi}_{t}\right), \\
T_{f t s}(t)=k_{t s}\left(\varphi_{t}-\varphi_{s}\right)+c_{t s}\left(\dot{\varphi}_{t}-\dot{\varphi}_{s}\right) .
\end{gathered}
$$

Equations (1), together with the expressions (2) and the initial state $\varphi_{p}\left(t_{0}\right)=\varphi_{p}^{0} \quad \varphi_{s}\left(t_{0}\right)=\varphi_{s}^{0}, \quad \varphi_{t}\left(t_{0}\right)=\varphi_{t}^{0}, \quad \dot{\varphi}_{p}\left(t_{0}\right)=\dot{\varphi}_{p^{\prime}}^{0} \quad \dot{\varphi}_{s}\left(t_{0}\right)=\dot{\varphi}_{s}^{0}, \quad \dot{\varphi}_{s}\left(t_{0}\right)=\dot{\varphi}_{s}^{0} \quad$, constitute the mathematical model of the vehicle drivetrain equipped with a TMF.

Note that the considered TMF inherently comprises five different concepts of torsional vibration absorbers. The first concept is depicted in Figure 1 and corresponds to the case when all three flywheels are interconnected via stiffness and damping components. This concept of the absorber will be termed as psptsTMF. When the tertiary flywheel is not connected to the secondary flywheel, that is, for $k_{t s}=c_{t s}=0$, Figure 1 presents the concept of the absorber termed as psptTMF. In the case when the tertiary flywheel is not connected to the primary flywheel, that is, for $k_{p t}=c_{p t}=0$, Figure 1 presents the third concept of the absorber-pstsTMF. If there is no coupling between the primary and secondary flywheels, that is, for $k_{p s}=c_{p s}=0$, Figure 1 will represent the fourth concept of the absorber termed ptsTMF. Finally, if the tertiary flywheel is absent, then the absorber becomes a conventional DMF and Equations (1), together with the first expression in Equation (2), and conditions of

$$
J_{t}=k_{p t}=k_{t s}=c_{p t}=c_{t s}=0
$$

describe the torsional vibration dynamics of the vehicle drivetrain with a conventional DMF. 
In addition to the sketch of the TMF depicted in Figure 1, several sketches of the TMF can be found in [37] with a detailed description of the components, giving an understanding of practical possible difficulties in the design of triple mass absorbers. In making TMF for applications in vehicle powertrains, possible practical difficulties can arise owing to limited installation space, reliability of components, and cost, among others.

Below, all above introduced concepts of the torsional vibration absorbers are subject for optimization and analysis.

The torsional vibration dynamics of the system in question will be studied on the set of drivetrain operational scenarios defined by the expression

$$
\text { OSs }=\left\{T_{e}(t), T_{g}(t), \quad \mathbf{q}(t), t \in\left[t_{0}, t_{f}\right], \quad \mathbf{d} \in \Omega\right\}
$$

where

$$
\begin{gathered}
T_{e}(t)=T_{m}+a_{e} \sin \left(\omega_{n_{0}} t\right), \quad \omega_{n_{0}}=n_{0} \omega, \quad \omega=2 \pi n_{e} / 60, \\
T_{g}(t)=k_{v}\left(\varphi_{s}-\varphi_{v}\right)+c_{v}\left(\dot{\varphi}_{s}-\dot{\varphi}_{v}\right), \quad \varphi_{v}(t)=\omega_{v} t .
\end{gathered}
$$

Here, in expressions (4)-(6), the engine driving torque $T_{e}(t)$ is modelled by the constant mean torque $T_{m}$ plus harmonic function describing the torque excitation; $\omega_{n_{0}}$ is the $n_{0}$-engine order vibration frequency, that is, $n_{0}$ times the angular velocity $\omega$; and $n_{e}$ is the engine speed in rpm. The torque at the transmission input shaft $T_{g}(t)$ is modelled by the expressions (6), and $k_{v}, c_{v}$ are equivalent torsional stiffness and damping coefficients of the load transmission system, and $\varphi_{v}, \omega_{v}$ are absolute angle of rotation and angular velocity of the transmission input shaft. $\mathbf{q}(t)=\left[\varphi_{p}(t), \varphi_{s}(t), \varphi_{t}(t)\right]^{T}$ is a vector of generalized coordinates, $\mathbf{d}=\left[J_{p}, J_{s}, J_{t}, k_{p s}, c_{p s}, k_{p t}, c_{p t}, k_{t s}, c_{t s}\right]^{T}$ is a vector of design parameters of a TMF, and $\Omega$ is a set of admissible values of the design parameters.

The third engine order vibration harmonic is focused on in the analysis as one of the most significant contributions to the oscillatory response in the drivetrain system of heavy-duty trucks with four-stroke, six-cylinder engines [24], that is, in all simulations, the engine order vibration frequency $n_{0}$ is chosen to be equal to 3 . The engine speed $n_{e}$ was chosen in the range of $600 \mathrm{rpm}-2000 \mathrm{rpm}$. The values for the parameters of the torque $T_{g}(t)$ at the transmission input shaft are as follows: $k_{v}=100,000 \mathrm{Nm} / \mathrm{rad}, c_{v}=0.1 \mathrm{Nms} / \mathrm{rad}$, and $\omega_{v}=\omega_{n_{0}} / 3$.

\section{Global Sensitivity Analysis}

Consider the vector

$$
\mathbf{d}=\left[J_{p}, J_{s}, J_{t}, k_{p s}, c_{p s}, k_{p t}, c_{p t}, k_{t s}, c_{t s}\right]^{T}=\left[d_{1}, \ldots, d_{9}\right]^{T} \in \Omega,
$$

and the objective functions

$$
\begin{gathered}
F_{1}(\mathbf{d})=\int_{600}^{2000} \operatorname{std}\left(T_{g}\left[\mathbf{d}, n_{e}\right]\right) d n_{e}, \quad F_{2}(\mathbf{d})=J_{p}+J_{s}+J_{t}, \\
F_{3}(\mathbf{d})=\int_{600}^{2000} \operatorname{std}\left(T_{f p s}\left[\mathbf{d}, n_{e}\right]\right) d n_{e}, \quad F_{4}(\mathbf{d})=\int_{600}^{2000} s t d\left(T_{f p t}\left[\mathbf{d}, n_{e}\right]\right) d n_{e}, \\
F_{5}(\mathbf{d})=\int_{600}^{2000} \operatorname{std}\left(T_{f t s}\left[\mathbf{d}, n_{e}\right]\right) d n_{e},
\end{gathered}
$$

as the vector of design parameters and the quality measures of performance of a TMF. The objective function $F_{1}(\mathbf{d})$ characterizes the standard deviation of oscillations of the torque at the transmission input 
shaft in the operating engine speed range $600 \mathrm{rpm} \leq n_{e} \leq 2000 \mathrm{rpm}$ The function $F_{2}(\mathbf{d})$ characterizes the mass inertia of a TMF and is relevant for estimation of the total weight and installation space of the absorber. The objective functions (9) and (10) characterize the friction torques and energy dissipation at the stiffness-damping interface of a TMF.

In this paper, the global sensitivity analysis (GSA) is used to study how the variation of the design parameters affect the chosen objective functions $F_{m}(\mathbf{d}), m=1, \ldots 5$. The total sensitivity index of the objective function $F_{m}(\mathbf{d})$ is determined by the following expression [39]:

$$
S_{i}^{\mathrm{T}}\left(F_{m}\right) \approx \frac{1-\alpha_{i}^{2} / \beta_{i}}{1-\left(\prod_{j=1}^{k} \alpha_{j}^{2} / \beta_{j}\right)}
$$

Here, $\alpha_{j} \approx \sum_{l=1}^{N} w_{j l} F_{m}\left(d_{j l}, \mathbf{c}_{-j l}\right), \quad \beta_{j} \approx \sum_{l=1}^{N} w_{j l}\left[F_{m}\left(d_{j l}, \mathbf{c}_{-j l}\right)\right]^{2}, F_{m}\left(d_{i}, \mathbf{c}_{-i}\right)$ denotes the function value for the case that all inputs except $d_{i}$ are fixed at their respective cut point coordinates, $\mathbf{c}=\left[\mathbf{c}_{1}, \ldots, c_{k}\right]^{\mathrm{T}}$; $N$ is the total number of integration points; and $d_{j l}$ and $w_{j l}$ are the $l$ th Gaussian integration abscissas and corresponding weight, respectively. More details on the algorithm of the GSA and its application can be found in [19,39-41].

The following problem is formulated.

Problem GSA. For given feasible operational scenario $\mathbf{O S} \in \mathbf{O S} s$ defined by the expressions (4)-(6), it is required, using relationship Equation (11), to determine the total sensitivity indices $S_{i}^{T}\left(F_{m}\right)$ of the objective functions (8)-(10) for all varying design parameters Equation (7), subject to Equations (1), given the initial state and the restriction $\mathbf{d} \in \Omega$.

The solution of the Problem GSA was obtained by using in-house developed computer code SAMO [42]. The SAMO stands for Sensitivity Analysis and Multi-objective Optimization (SAMO) and is a computer code implemented in MATLABC to carry out a computationally efficient global sensitivity analysis and multi-objective optimization of engineering systems. The sensitivity analysis works based on the multiplicative dimensional reduction method [39]. To carry out the multi-objective optimization the genetic algorithm is used [33]. More details how simulation is conducted can be found in SAMO Tutorial [42].

The nominal values of the absorber's design parameters were chosen as follows:

$$
\begin{gathered}
J_{p}=1.8 \mathrm{kgm}^{2}, \quad J_{s}=0.9 \mathrm{kgm}^{2}, \quad k_{p s}=12732 \mathrm{Nm} / \mathrm{rad}, \quad c_{p s}=30 \mathrm{Nms} / \mathrm{rad} \\
J_{t}=0.3 \mathrm{kgm}^{2}, \quad k_{p t}=k_{t s}=2000 \mathrm{Nm} / \mathrm{rad}, \quad c_{p t}=c_{t s}=30 \mathrm{Nms} / \mathrm{rad} .
\end{gathered}
$$

The values of the design parameters (12) are feasible for application of the DMF in heavy-duty truck drivetrain systems [24].

The analysis was done using nominal values (12) and (13), a normal distribution of the varying parameters with coefficient of variation equal to 0.1 , and the following lower and upper bounds for design parameters:

$$
\Omega=\left\{\begin{array}{l}
J_{p} \in[0.2,2.4], \quad J_{s} \in[0.1,1.2], \quad J_{t} \in[0.05,0.45] \\
k_{p s}, k_{p t}, k_{t s} \in[2000,12,000], \quad c_{p s}, c_{p t}, c_{t s} \in[0,150]
\end{array}\right\}
$$

The solutions of problem GSA obtained for the psptsTMF in the case of low and high levels of mean value of engine driving torque $T_{e}(t)$ in the operation engine speed range $600 \mathrm{rpm} \leq n_{e} \leq 2000 \mathrm{rpm}$ are shown in Figure $2 \mathrm{a}, \mathrm{b}$. The solution is presented by means of mapping between the design parameters $J_{p}, J_{s}, J_{t}, k_{p s}, c_{p s}, k_{p t}, c_{p t}, k_{t s}, c_{t s}$ and the values of the total sensitivity indices of the objective functions (8)-(10). 


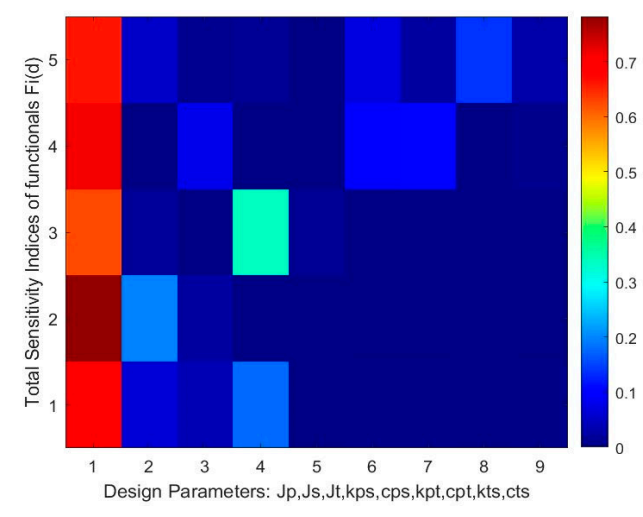

(a)

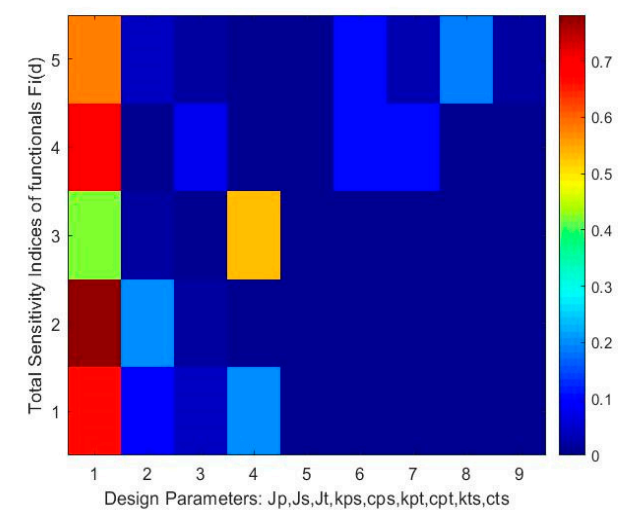

(b)

Figure 2. Sensitivity indices of the objective functions (8)-(10) for the drivetrain equipped with the psptsTMF: (a) for $T_{m}=300 \mathrm{Nm}, a_{e}=500 \mathrm{Nm}$; (b) for $T_{m}=3000 \mathrm{Nm}, a_{e}=3000 \mathrm{Nm}$.

\section{Weight-Vibration Pareto Optimization}

The Pareto optimization problem for the vehicle drivetrain equipped with a TMF is formulated as follows.

Problem WV-PO. For given feasible operational scenario $\mathbf{O S} \in \mathbf{O S} s$ defined by the expressions (4)-(6), it is required to determine the vector of the design parameters of the TMF

$$
\mathbf{d}=\left[J_{p}^{*}, J_{s}^{*}, J_{t}^{*}, k_{p s}^{*}, c_{p s}^{*}, k_{p t}^{*}, c_{p t}^{*}, k_{t s}^{*}, c_{t s}^{*}\right]^{T}=\mathbf{d}^{*}
$$

and the vector of generalized coordinates $\mathbf{q}(t)=\mathbf{q}^{*}(t)$ that satisfy the system of variational Equations

$$
\left\{\begin{array}{l}
\min _{\mathbf{d} \in \Omega}\left\{\frac{1}{T_{m}} \int_{600}^{2000} \operatorname{std}\left(T_{g}\left[\mathbf{q}(t), \mathbf{d}, n_{e}\right]\right) d n_{e}\right\}=\frac{1}{T_{m}} \int_{600}^{2000} \operatorname{std}\left(T_{g}\left[\mathbf{q}^{*}(t), \mathbf{d}^{*}, n_{e}\right]\right) d n_{e}=\widetilde{F}_{1}\left(\mathbf{d}^{*}\right) \\
\min _{\mathbf{d} \in \Omega}\left\{\left(J_{p}+J_{s}+J_{t}\right) / J_{\max }\right\}=\left(J_{p}^{*}+J_{s}^{*}+J_{t}^{*}\right) / J_{\max }
\end{array},\right.
$$

subject to differential Equations (1), given initial state and the restrictions on the design parameters Equation (14).

The Equation (16) express the requirements on the vector of design parameters $\mathbf{d}^{*}$ and the vector of generalized coordinates $\mathbf{q}^{*}(t)$ to guarantee the best attenuation of oscillation of the torque at the transmission input shaft, and at the same time to minimize the total mass inertia of the vibration absorber.

The solutions of the problem WV-PO for all five torsional vibration absorbers, that is, for the psptsTMF, the psptTMF, the pstsTMF, the ptsTME, and for the DMF, were obtained using the computer code SAMO [42]. The setting of the genetic algorithm for optimization was as follows: population size $=100$, number of generations $=100$, elite count $=4$, and Pareto fraction $=1$.

The Pareto fronts between the normalized objective functions $\widetilde{F}_{1}(\mathbf{d})=\frac{1}{T_{m}} \int_{600}^{2000} \operatorname{std}\left(T_{g}\left[\mathbf{q}(t), \mathbf{d}, n_{e}\right]\right) d n_{e}$ and $\widetilde{F}_{2}(\mathbf{d})=\left(J_{p}+J_{s}+J_{t}\right) / J_{\max }$, obtained by solving the above formulated optimization problem, are shown in Figure $3 a, b$. 


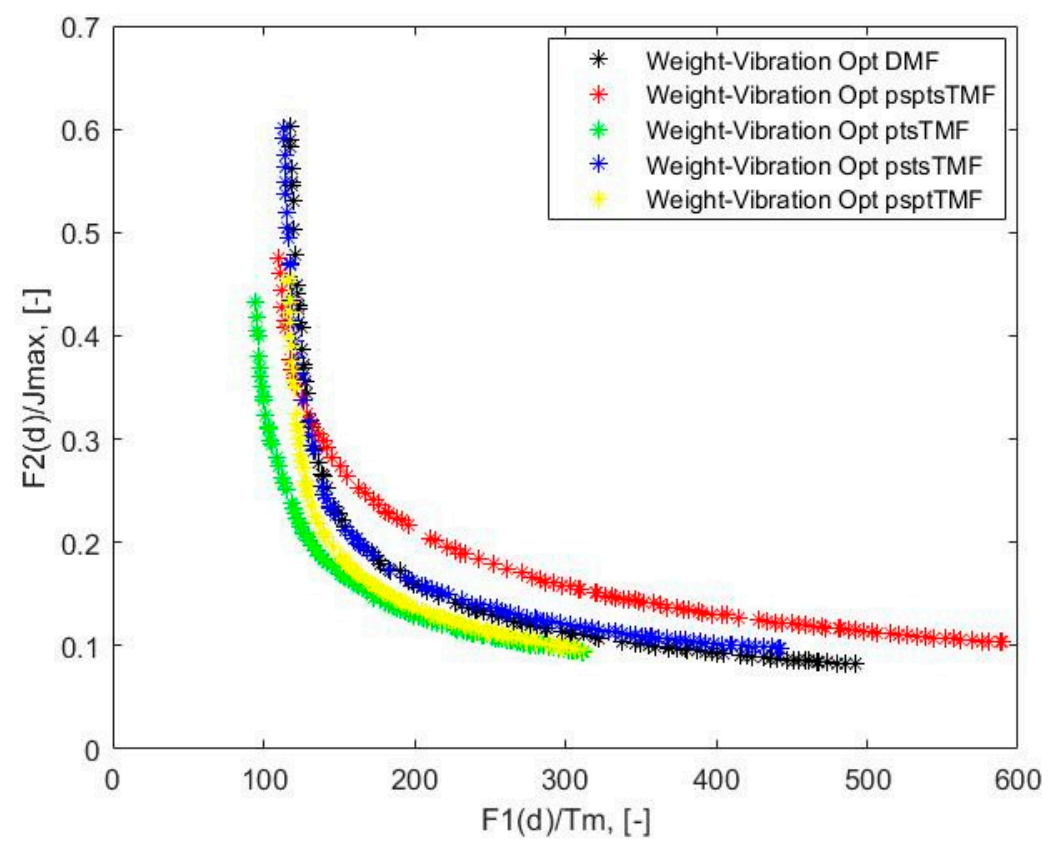

(a)

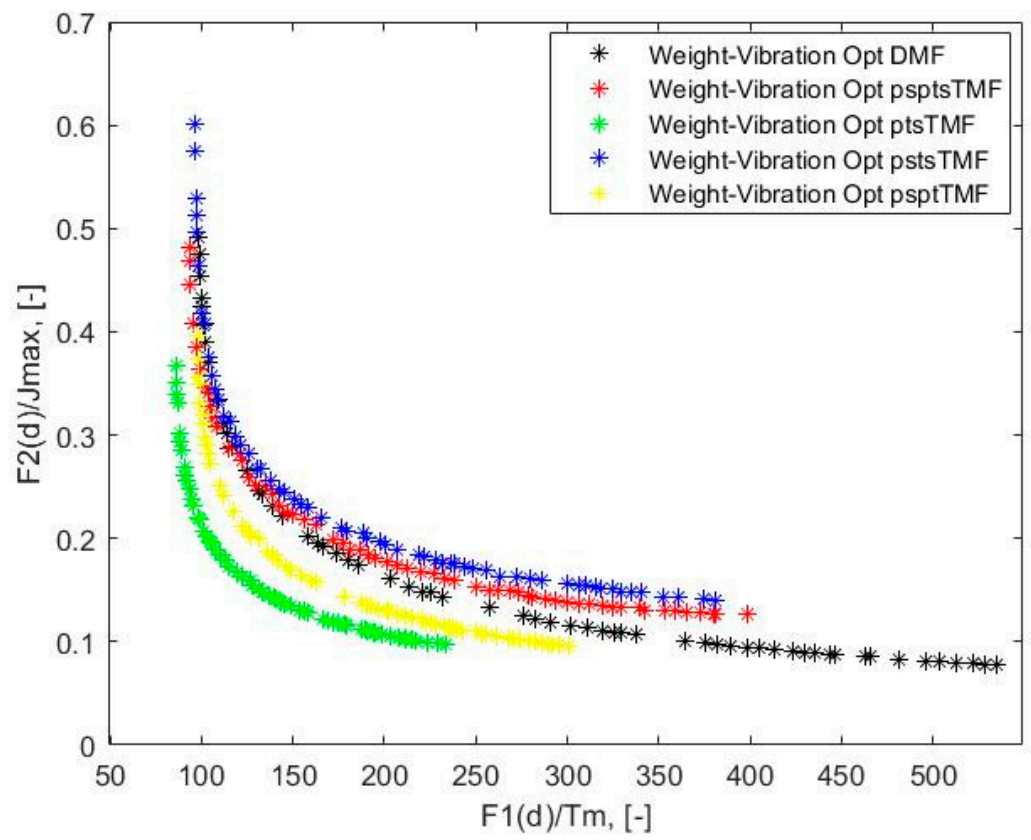

(b)

Figure 3. Pareto fronts for the drivetrain with the TMF in operating engine speed range $600 \mathrm{rpm} \leq n_{e} \leq 2000 \mathrm{rpm}$ : (a) for $T_{m}=300 \mathrm{Nm}, a_{e}=500 \mathrm{Nm}$; (b) for $T_{m}=3000 \mathrm{Nm}, a_{e}=3000 \mathrm{Nm}$; $J_{\max }=4.05 \mathrm{~kg} \mathrm{~m}^{2}$. DMF, dual mass flywheel.

The red curves in Figure 3a,b correspond to the results of weight-vibration bi-objective optimization of the TMF with respect to all design parameters Equation (15). The green curves are the Pareto fronts of optimization of the TMF in the case of $k_{p s}=c_{p s}=0$. The black curves correspond to the results of optimization for the drivetrain equipped with the DMF, that is, to the solution of problem WV-PO when the structure of the TMF satisfies the conditions Equation (3). The blue curves are the Pareto fronts obtained in case when the tertiary flywheel is connected only to the secondary flywheel. The yellow 
curves represent the results of weight-vibration bi-objective optimization of the TMF with tertiary flywheel connected only to the primary flywheel.

Every point of the Pareto front corresponds to the vector of the design parameters $\mathbf{d}^{*}$ and the respective vector of generalized coordinates $\mathbf{q}(t)=\mathbf{q}^{*}(t)$ of the absorber. The obtained values of the design parameters Equation (15) minimizing the objective function $\widetilde{F}_{1}(\mathbf{d})=\frac{1}{T_{m}} \int_{600}^{2000} \operatorname{std}\left(T_{g}\left[\mathbf{q}(t), \mathbf{d}, n_{e}\right]\right) d n_{e}$ for the considered vibration absorbers in operating engine speed range $600 \mathrm{rpm} \leq n_{e} \leq 2000 \mathrm{rpm}$ with the mean value of the engine driving torque $T_{m}=300 \mathrm{Nm}$ and the amplitude of its harmonic excitation $a_{e}=500 \mathrm{Nm}$, as well as for the $T_{m}=3000 \mathrm{Nm}$ and $a_{e}=3000 \mathrm{Nm}$, are presented in Tables 1 and 2, respectively.

Table 1. Results of the solution of problem weight-vibration Pareto optimization (WV-PO), $T_{m}=300 \mathrm{Nm}$, $a_{e}=500 \mathrm{Nm}$. TMF, triple mass flywheel; DMF, dual mass flywheel.

\begin{tabular}{|c|c|c|c|c|c|}
\hline $\begin{array}{l}\text { Optimized Design Parameters } \\
\mathrm{d}^{*}=\left[J_{p}^{*}, J_{s}^{*}, J_{t}^{*}, k_{p s}^{*}, c_{p s}^{*}, k_{p t}^{*}, c_{p t}^{*}, k_{t s}^{*}, c_{t s}^{*}\right]^{T}\end{array}$ & psptsTMF & $\begin{array}{c}\operatorname{psptTMF} \\
\left(k_{t s}=c_{t s}=0\right)\end{array}$ & $\begin{array}{c}\text { pstsTMF } \\
\left(k_{p t}=c_{p t}=0\right)\end{array}$ & $\begin{array}{c}\text { ptsTMF } \\
\left(k_{p s}=c_{p s}=0\right)\end{array}$ & $\begin{array}{l}\text { DMF } \\
J_{t}=0\end{array}$ \\
\hline$J_{p}^{*},\left(\mathrm{kgm}^{2}\right)$ & 1.48 & 1.67 & 1.98 & 1.50 & 2.34 \\
\hline$J_{s}^{*},\left(\mathrm{kgm}^{2}\right)$ & 0.11 & 0.10 & 0.10 & 0.11 & 0.10 \\
\hline$J_{t}^{*},\left(\mathrm{kgm}^{2}\right)$ & 0.34 & 0.08 & 0.35 & 0.14 & - \\
\hline$k_{p s}^{*},(\mathrm{Nm} / \mathrm{rad})$ & 2683 & 3132 & 3165 & - & 3938 \\
\hline$c_{p s}^{*},(\mathrm{Nms} / \mathrm{rad})$ & 18 & 21 & 27 & - & 30 \\
\hline$k_{p t^{\prime}}^{*}(\mathrm{Nm} / \mathrm{rad})$ & 6216 & 7399 & - & 3033 & - \\
\hline$c_{p t^{\prime}}^{*}(\mathrm{Nms} / \mathrm{rad})$ & 12 & 74 & - & 91 & - \\
\hline$k_{t s^{\prime}}^{*}(\mathrm{Nm} / \mathrm{rad})$ & 2764 & - & 7502 & 4995 & - \\
\hline$c_{t s^{\prime}}^{*}(\mathrm{Nms} / \mathrm{rad})$ & 12 & - & 29 & 9 & - \\
\hline$\widetilde{F}_{1}\left(\mathbf{d}^{*}\right),(-)$ & 110 & 117 & 114 & 95 & 118 \\
\hline$J=J_{p}+J_{s}+J_{t},\left(\mathrm{kgm}^{2}\right)$ & 1.93 & 1.85 & 2.43 & 1.75 & 2.44 \\
\hline
\end{tabular}

Table 2. Results of the solution of problem WV-PO, $T_{m}=3000 \mathrm{Nm}, a_{e}=3000 \mathrm{Nm}$.

\begin{tabular}{|c|c|c|c|c|c|}
\hline $\begin{array}{l}\text { Optimized Design Parameters } \\
\mathrm{d}^{*}=\left[J_{p}^{*}, J_{s,}^{*} J_{t}^{*}, k_{p s}^{*}, c_{p s}^{*}, k_{p t}^{*}, c_{p t}^{*}, k_{t s}^{*}, c_{t s}^{*}\right]^{T}\end{array}$ & psptsTMF & $\begin{array}{c}\text { psptTMF } \\
\left(k_{t s}=c_{t s}=0\right)\end{array}$ & $\begin{array}{c}\text { pstsTMF } \\
\left(k_{p t}=c_{p t}=0\right)\end{array}$ & $\begin{array}{c}\text { ptsTMF } \\
\left(k_{p s}=c_{p s}=0\right)\end{array}$ & $\begin{array}{l}\mathrm{DMF} \\
J_{t}=0\end{array}$ \\
\hline$J_{p}^{*},\left(\mathrm{kgm}^{2}\right)$ & 1.44 & 1.43 & 1.98 & 1.30 & 1.88 \\
\hline$J_{s}^{*},\left(\mathrm{kgm}^{2}\right)$ & 0.11 & 0.11 & 0.10 & 0.11 & 0.11 \\
\hline$J_{t}^{*},\left(\mathrm{kgm}^{2}\right)$ & 0.40 & 0.07 & 0.35 & 0.08 & - \\
\hline$k_{p s}^{*}(\mathrm{Nm} / \mathrm{rad})$ & 2843 & 3201 & 3334 & - & 3069 \\
\hline$c_{p s}^{*}(\mathrm{Nms} / \mathrm{rad})$ & 25 & 25 & 37 & - & 33 \\
\hline$k_{p t^{\prime}}^{*}(\mathrm{Nm} / \mathrm{rad})$ & 6332 & 7190 & - & 4309 & - \\
\hline$c_{p t^{\prime}}^{*}(\mathrm{Nms} / \mathrm{rad})$ & 17 & 71 & - & 124 & - \\
\hline$k_{t s}^{*},(\mathrm{Nm} / \mathrm{rad})$ & 3786 & - & 7349 & 5142 & - \\
\hline$c_{t s^{\prime}}^{*}(\mathrm{Nms} / \mathrm{rad})$ & 18 & - & 29 & 14 & - \\
\hline$\widetilde{F}_{1}\left(\mathbf{d}^{*}\right),(-)$ & 94 & 98 & 96 & 86 & 99 \\
\hline$J=J_{p}+J_{s}+J_{t},\left(\mathrm{kgm}^{2}\right)$ & 1.94 & 1.61 & 2.43 & 1.49 & 1.99 \\
\hline
\end{tabular}




\section{Discussion}

The chosen objective functions (8)-(10) are appropriate to focus the design process for the vibration absorber on the best attenuation of the oscillation of the torque at the transmission input shaft, to minimize total mass inertia, as well as to analyze the energy dissipation in the stiffness-damping interface of the absorber.

The results of the GSA of the performance of TMF, presented in Section 3 (Figure 2a,b), make it possible to conclude the following. For the drivetrain system in the operating engine speed range $600 \mathrm{rpm} \leq n_{e} \leq 2000 \mathrm{rpm}$, with both low and high mean values of the engine driving torques, the moment of inertia of the primary flywheel, $J_{p}$, as well as the stiffness between the primary and secondary flywheels, $k_{p s}$, mostly affect the oscillation of the torque at the transmission input shaft and the energy dissipation of the vibration absorber (Figure $2 a, b$, sensitivity indices for $F_{1}(\mathbf{d})$ and $F_{3}(\mathbf{d})$ ). The energy dissipation in the stiffness-damping interface between the primary and the tertiary flywheels, and between the tertiary and the secondary flywheels, are mostly affected by the moment of inertia of the tertiary flywheel, $J_{t}$, and the parameters $k_{p t}, c_{p t}$ and $k_{t s}, c_{t s}$, respectively, (Figure 2a,b, sensitivity indices for $F_{4}(\mathbf{d})$ and $\left.F_{5}(\mathbf{d})\right)$.

The solutions of the Pareto optimization problem, presented in Section 4, show that there exists a trade-off between the measure of the oscillation attenuation of the torque at the transmission input shaft and the total mass inertia characteristic of the drivetrain system equipped with the TMF in the operating engine speed range $600 \mathrm{rpm} \leq n_{e} \leq 2000 \mathrm{rpm}$ for both low and high mean values of the engine driving torques (Figure 3a,b). Analysis of the obtained Pareto fronts shows that at least two concepts of the TMF, namely the ptsTMF (green curves) and the psptTMF (yellow curves), are in significant superior positions in comparison with the optimized DMF (black curves). As follows from the values of $\widetilde{F}_{1}\left(\mathbf{d}^{*}\right)$ for the ptsTMF and the DMF (Tables 1 and 2 ), the use of the optimized in the drivetrain system improves up to $20 \%$ the attenuation of the oscillations of the torque at the transmission input shaft in comparison with the attenuation of the oscillations of the torque in the case of using the optimized DMF.

The standard deviation of the torques at the transmission input shaft as a function of the engine speed $n_{e}$ in the range of $50 \mathrm{rpm} \leq n_{e} \leq 2000 \mathrm{rpm}$ are depicted in Figure $4 \mathrm{a}, \mathrm{b}$ for the DMF with nominal design parameters (12) (dashed curve), and for the weight-vibration optimized DMF (solid black curve), the ptsTMF (green curve), and the psptsTMF (red curve). Zoomed plots of these curves are presented in Figure 5a,b, respectively.

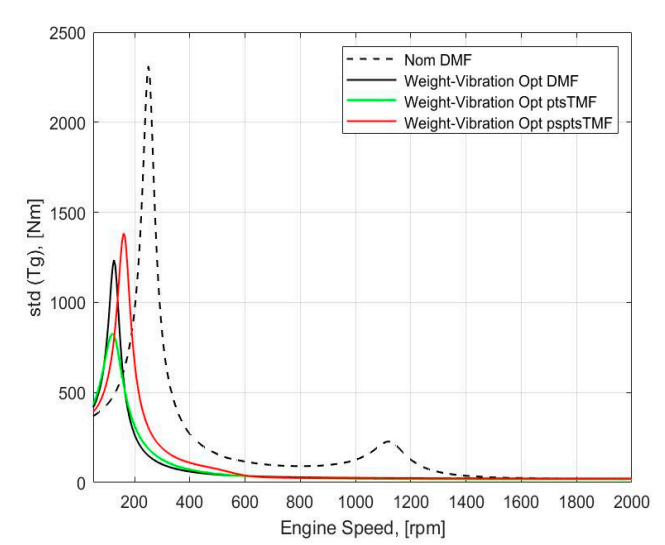

(a)

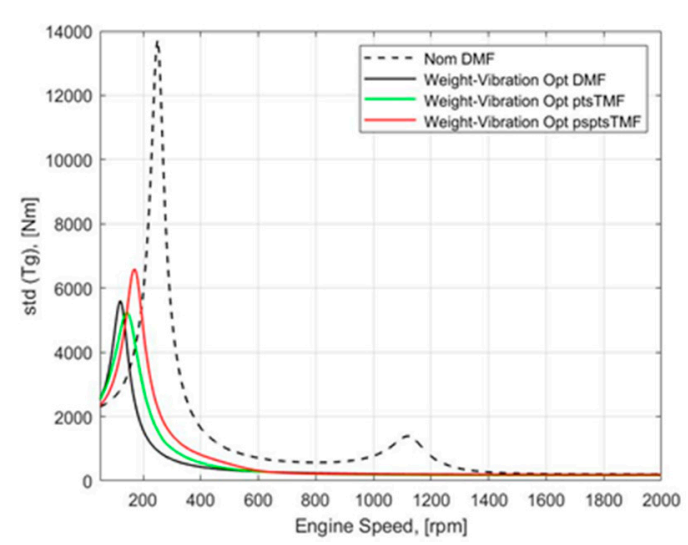

(b)

Figure 4. Engine speed history of standard deviation of the torques at the transmission input shaft for the DMF with nominal values of design parameters (12) and for vibration absorbers with obtained optimized design parameters: (a) for $T_{m}=300 \mathrm{Nm}, a_{e}=500 \mathrm{Nm}$; (b) for $T_{m}=3000 \mathrm{Nm}, a_{e}=3000 \mathrm{Nm}$. 


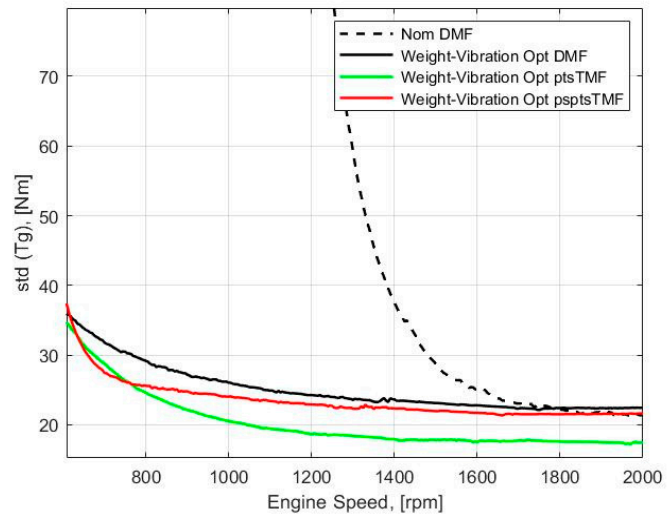

(a)

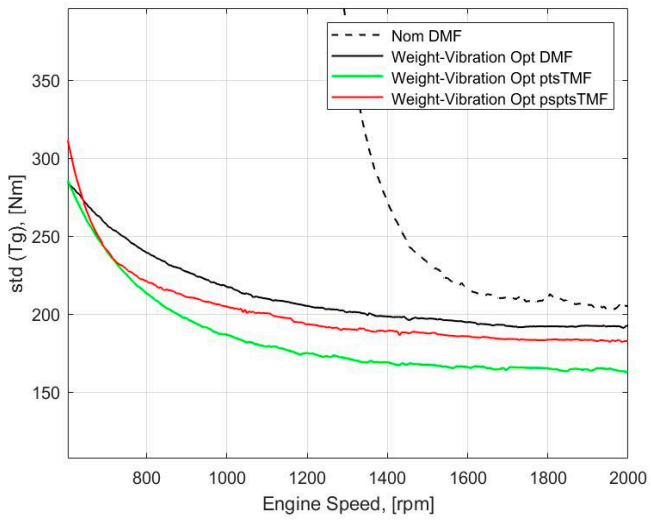

(b)

Figure 5. Zoomed plots of the engine speed history of the standard deviation of the torques at the transmission input shaft for the DMF with nominal values of design parameters (12) and for optimized vibration absorbers: (a) for $T_{m}=300 \mathrm{Nm}, a_{e}=500 \mathrm{Nm}$; (b) for $T_{m}=3000 \mathrm{Nm}, a_{e}=3000 \mathrm{Nm}$.

Analysis of Figures 4 and 5 shows that, using weight-vibration optimized absorbers, the efficiency of the attenuation of the oscillations of the torque at the transmission input shaft in the drivetrain system has significantly increased in comparison with the performance of the DMF with nominal design parameters. Both resonance peaks of the dashed curves are significantly reduced in the case of using the weight-vibration optimized DMF, the ptsTMF, as well as the psptsTMF. The best attenuation of the oscillations of the torque at the transmission input shaft in the drivetrain system is provided by the weight-vibration optimized ptsTMF (green curves in Figures 4 and 5).

Figure $6 \mathrm{a}, \mathrm{b}$ present the time history of the torques at the transmission input shaft in the drivetrain system for operating engine speed $n_{e}=1200 \mathrm{rpm}$, illustrating how much the weight-vibration optimized DMF (solid black curve), the ptsTMF (green curve), and the psptsTMF (red curve) enhance the attenuation of the torque oscillations in comparison with the DMF with nominal design parameters (12) (dashed curve).

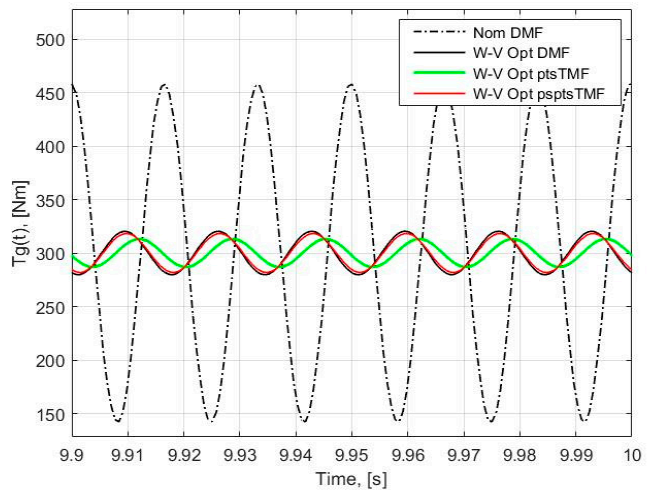

(a)

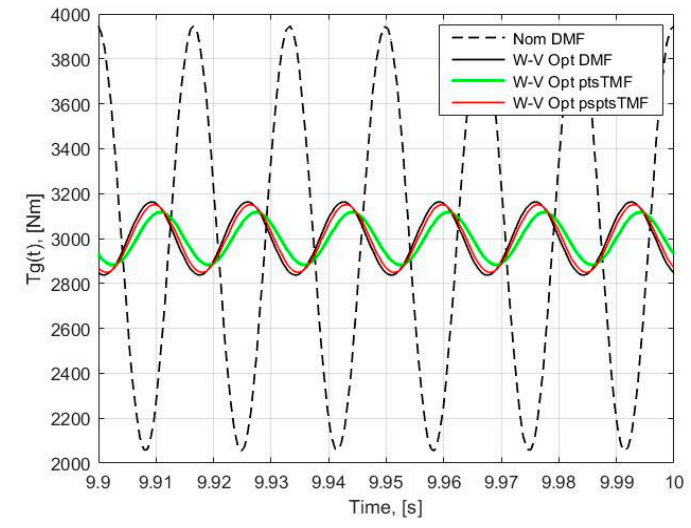

(b)

Figure 6. The torques at the transmission input shaft for operating engine speed $n_{e}=1200 \mathrm{rpm}$ for the DMF with nominal values of design parameters (12) and for vibration absorbers with obtained optimized design parameters: (a) for $T_{m}=300 \mathrm{Nm}, a_{e}=500 \mathrm{Nm}$; (b) for $T_{m}=3000 \mathrm{Nm}, a_{e}=3000 \mathrm{Nm}$.

The quantitative analysis of the obtained values of the design parameters shows that the weight-vibration Pareto optimization of all five concepts of the TMF resulted in much lower values of the total mass inertia $J=J_{p}+J_{s}+J_{t}$ of the optimized absorbers in comparison with the total mass inertia of the nominal DMF (see the last rows in Tables 1 and 2, and the design parameters (12)). 
For instance, the total mass inertia of the optimized pstTMF is up to $28 \%$ less in comparison with the total mass inertia of the optimized DMF (see Table 1). The above mentioned is a significant advantage of the weight-vibration optimized TMF for its implementation in real drivetrain systems.

\section{Conclusions and Outlook}

The results obtained demonstrate the efficiency of the methodology based on global sensitivity analysis and Pareto optimization for the design of novel multiple-mass torsional vibration absorbers for vehicle powertrains. The methodology can also be used for multi-objective optimal design of torsional vibration absorbers for other rotor-dynamical systems subjected to oscillatory excitations. The following concluding remarks can be drawn.

- There exists evidence of feasibility of the application of weight-vibration optimized triple mass flywheels in heavy-duty trucks powertrains.

- For a heavy-duty truck powertrain equipped with a triple mass flywheel, there exists the weight-vibration bi-objective optimized mass inertia, as well as stiffness and damping parameters providing the trade-off between the level of attenuation of the oscillations of the torque at the transmission input shaft and the total mass inertia of the absorber in the operating engine speed range $600 \mathrm{rpm} \leq n_{e} \leq 2000 \mathrm{rpm}$ when the third engine order vibration harmonic is in focus.

- The weight-vibration optimized design parameters of a triple mass flywheel providing the best attenuation of oscillations of the torque at the transmission input shaft can put this concept in a superior position in comparison with the weight-vibration optimized dual mass flywheel.

The above-mentioned points highlight the advantages of triple mass flywheels for technology of torsional vibration attenuation in vehicle powertrains.

Design optimization problems for a triple-mass flywheel within a complete model of a drivetrain system of a heavy-duty truck, as well as validation of the results obtained using experimental data, are important steps for future research $[18,43]$.

Funding: This research was partially funded by the Swedish Energy Agency, project No. 42100-1.

Conflicts of Interest: The author declares no conflict of interest.

\section{References}

1. Albers, A. Advanced development of dual mass flywheel (DMFW) design-noise control for today's automobiles. In 5th LuK Symposium; Schaeffler: Bühl, Germany, 1994; pp. 24-41.

2. Kim, T.H.; Song, H.L.; Hwang, S.H.; Kim, H.S. Analysis of dual mass flywheel using discreet arcspring model. Key Eng. Mater. 2006. [CrossRef]

3. Mahl, T.; Sawodny, O. Modelling of an automotive dual mass flywheel. In IFAC Proceedings; IFAC: Laxenburg, Austria, 2010; Volume 43, pp. 517-523. [CrossRef]

4. Song, L.Q.; Zeng, L.P.; Zhang, S.P.; Zhou, J.D.; Niu, H.E. Design and analysis of a dual mass flywheel with continuously variable stiffness based on compensation principle. Mech. Mach. Theory 2014, 79, 124-140. [CrossRef]

5. Chen, L.; Zeng, R.; Jiang, Z. Nonlinear dynamical model of an automotive dual mass flywheel. Adv. Mech. Eng. 2015, 7, 1-11. [CrossRef]

6. Fidlin, A.; Mall, P. On the effect of the distributed friction in the arc spring on the dynamic behavior of the automotive transmission. In Proceedings of the International Conference on Engineering Vibrations, ICoEV 2015; National and University Library of Slovenia: Ljubljana, Slovenia, 2015; pp. 1099-1108.

7. Gupta, K.; Choudhary, A.; Bidre, R. NVH Performance Improvement Study Using a Dual Mass Flywheel (DMF), Inertia Ring Type Tuned Torsional Vibration Damper (TVD) and Single Mass Flywheel (SMF) in a Front Engine and Rear Wheel Driveline Architecture. SAE Tech. Pap. 2017. [CrossRef]

8. Mall, P.; Fidlin, A.; Krüger, A.; Groß, H. Simulation based optimization of torsional vibration dampers in automotive powertrains. Mech. Mach. Theory 2017, 115, 244-266. [CrossRef] 
9. Faust, H. Powertrain systems of the future-engine, transmission and damper systems for downspeeding, downsizing and cylinder deactivation. In 10th Schaeffler Symposium; Schaeffler Technologies GmbH \& Co. KG: Baden-Baden, Germany, 2014; pp. 24-41. [CrossRef]

10. Haddow, A.; Shaw, S. Centrifugal Pendulum Vibration Absorbers: An Experimental and Theoretical Investigation. Nonlinear Dyn. 2003, 34, 293-307. [CrossRef]

11. Haris, A.; Motato, E.; Theodossiades, S.; Rahnejat, H.; Kelly, P.; Vakakis, A.; Bergman, L.; McFarland, D.M. A study on torsional vibration attenuation in automotive drivetrains using absorbers with smooth and non-smooth nonlinearities. Appl. Math. Model. 2017, 46, 674-690. [CrossRef]

12. Kooy, A. Best-in-class dampers for every driveline concept. In Schaeffler Symposium; Schaeffler: Baden-Baden, Germany, 2018; pp. 146-160.

13. Haris, A.; Motato, E.; Mohammadpour, M.; Thedossiades, S.; Rahnejat, H.; O' Mahony, M.; Vakakis, A.F.; Bergman, L.A.; McFarland, D.M. On the effect of multiple parallel nonlinear absorbers in palliation of torsional response of automotive drivetrain. Int. J. Non-Linear Mech. 2017, 96, 22-35. [CrossRef]

14. Motato, E.; Haris, A.; Thedossiades, S.; Mohammadpour, M.; Rahnejat, H.; Kelly, P.; Vakakis, A.F.; McFarland, D.M.; Bergman, L.A. Targeted energy transfer and modal energy redistribution in automotive drivetrains. Nonlinear Dyn. 2017, 87, 169-190. [CrossRef]

15. Chen, Z.; Chen, Z.; Mao, Y.; Shi, W.; Zhang, G. Control Research of Power Train Torsional Vibration Based on Magneto-Rheological Fluid Dual Mass Flywheel. SAE Tech. Pap. 2014. [CrossRef]

16. Zu, Q.-h.; Chen, Z.-Y.; Shi, W.-K.; Mao, Y.; Chen, Z.-Y. Torsional Vibration Semiactive Control of Drivetrain Based on Magnetorheological Fluid Dual Mass Flywheel. Math. Probl. Eng. Hindawi Publ. Corp. 2015. [CrossRef]

17. Dong, X.; Li, W.; Yu, J.; Pan, C.; Xi, J.; Zhou, Y.; Wang, X. Magneto-Rheological Variable Stiffness and Damping Torsional Vibration Control of Powertrain System. Front. Mater. 2020. [CrossRef]

18. Wramner, L.; Berbyuk, V.; Johansson, H. Vibration dynamics in non-linear dual mass flywheels for heavy-duty trucks. In The 28th Edition of the Biennial ISMA Conference on Noise and Vibration Engineering; KU Leuven: Leuven, Belgium, 2018; pp. 1863-1876.

19. Berbyuk, V. Design optimization of torsional vibration absorbers for heavy-duty truck drivetrain systems. Vibration 2019, 2, 240-264. [CrossRef]

20. Berbyuk, V. Weight-vibration Pareto optimization of a dual mass flywheel. Math. Methods Phys. Fields 2019, 62, 7-18.

21. Berbyuk, V. Towards the limits of vibration attenuation in drivetrain system by torsional dynamics absorber. In Advances in Dynamics of Vehicles on Roads and Tracks. IAVSD 2019; Klomp, M., Bruzelius, F., Nielsen, J., Hillemyr, A., Eds.; Lecture Notes in Mechanical Engineering; Springer: Berlin/Heidelberg, Germany, 2020; pp. 1574-1583. [CrossRef]

22. Wramner, L. Dual mass flywheel with tuned vibration absorbers for application in heavy-duty truck powertrains. Proc. Inst. Mech. Eng. Part D J. Automob. Eng. 2020. [CrossRef]

23. Wramner, L. Analysis of power split vibration absorber performance in heavy-duty truck powertrains. Proc. Inst. Mech. Eng. Part D J. Automob. Eng. 2020. [CrossRef]

24. Wramner, L. Torsional Vibration Absorbers in Heavy-Duty Truck Powertrains. Ph.D. Thesis, Chalmers University of Technology, Göteborg, Sweden, 2020.

25. Den Hartog, J.P. Mechanical Vibrations; Dover Publication, Inc.: New York, NY, USA, 1985.

26. De Domenico, D.; Ricciardi, G. Optimal design and seismic performance of tuned mass damper inerter (TMDI) for structures with nonlinear base isolation systems. Earthq. Eng. Struct. Dyn. 2018, 47, 2539-2560.

27. Mousavi Bideleh, S.M.; Berbyuk, V. Pareto Optimization of a Nonlinear Tuned Mass Damper to Control Vibrations in Hand Held Impact Machines. In Nonlinear Dynamics, Volume 1. Conference Proceedings of the Society for Experimental Mechanics Series; Kerschen, G., Ed.; Springer: Berlin/Heidelberg, Germany, 2019; pp. 27-44. [CrossRef]

28. Seer, T.A.; Vahdati, N.; Shiryaev, O. Adaptive Torsional Tuned Vibration Absorber for Rotary Equipment. Vibration 2019, 2, 116-134. [CrossRef]

29. Karimaei, H.; Mehrgou, M.; Chamani, H.R. Optimisation of torsional vibration system for a heavy-duty inline six-cylinder diesel engine. Proc Imeche Part K J. Multi-Body Dyn. 2019, 233, 642-656. [CrossRef]

30. Bazara, S.; Shetty, C. Nonlinear Programming. Theory and Algorithms; John Wiley and Sons: New York, NY, USA, 1979. 
31. Bagchi, T.P. Multiobjective Scheduling by Genetic Algorithmsii; Kluwer Academic Publisher: Boston, MA, USA, 1999.

32. Tan, X.; Hua, L.; Lu, C.; Yang, C.; Wang, Y.; Wang, S. A new method for optimizing the parameters of torsional vibration dampers. J. Vibroeng. 2017, 19, 4155-4171.

33. McCall, J. Genetic algorithms for modelling and optimization. J. Comput. Appl. Math. 2005, 184, $205-222$. [CrossRef]

34. Maeda, Y.; Nishiwaki, S.; Izui, K.; Yoshimura, M.; Matsui, K.; Terada, K. Structural topology optimization of vibrating structures with specified eigenfrequencies and eigenmode shapes. Int. J. Numer. Methods Eng. 2006, 67, 597-628. [CrossRef]

35. Chronopoulos, D. Design optimization of composite structures operating in acoustic environments. J. Sound Vib. 2015, 355, 322-344. [CrossRef]

36. Kaveh, A.; Ghazaan, M.I. Vibrating particles system algorithm for truss optimization with multiple natural frequency constraints. Acta Mech. 2017, 218, 307-322. [CrossRef]

37. Shaw, W.L. Triple Mass Flywheel. U.S. Patent 2019/0011010 A1, 10 January 2019.

38. Olsson, H. Control Systems with Friction. Ph.D. Thesis, Lund Institute of Technology, Göteborg, Sweden, 1996.

39. Zhang, X.; Pandey, M.D. An effective approximation for variance-based global sensitivity analysis. Reliab. Eng. Syst. Saf. 2014, 121, 164-174. [CrossRef]

40. Rabitz, H.; Alis, Ö. General foundations of high-dimensional model representations. J. Math. Chem. 1999, 25, 197-233. [CrossRef]

41. Mousavi Bideleh, S.M.; Berbyuk, V. Global sensitivity analysis of bogie dynamics with respect to suspension components. Multibody Syst. Dyn. 2016, 37, 145-174. [CrossRef]

42. Mousavi Bideleh, S.M.; Berbyuk, V. A Computer Code for Sensitivity Analysis and Multiobjective Optimization: SAMO Tutorial; Department of Mechanics and Maritime Sciences, Chalmers University of Technology: Gothenburg, Sweden, 2017; p. 45.

43. Karlsson, J. Investigation of Dynamic Friction Properties of a Dual Mass Flywheel for Commercial Vehicles. Master's Thesis, Chalmers University of Technology, Göteborg, Sweden, 2018.

(C) 2020 by the author. Licensee MDPI, Basel, Switzerland. This article is an open access article distributed under the terms and conditions of the Creative Commons Attribution (CC BY) license (http://creativecommons.org/licenses/by/4.0/). 